\title{
EDUCAÇÃo FÍSICA E CINEMA: CONTEÚdOS DIDÁTICOS E DISCUSSÕES SOCIAIS A PARTIR DA EXPERIÊNCIA DE LEITURA POR ANDAIMES
}

\author{
PHYSICAL EDUCATION AND CINEMA: DIDACTIC CONTENT AND SOCIAL \\ DISCUSSIONS FROM THE SCAFFOLDING READING EXPERIENCE
}

\author{
Rosiele Oliveira da Encarnação \\ Mestre em Educação em Ciências \\ Universidade Federal de Santa Maria - UFSM. \\ Santa Maria, Rio Grande do Sul - Brasil. \\ rosiele_oliveira@live.com \\ ili \\ Gabriela Brum de Deus \\ Mestre em Educação em Ciências \\ Universidade Federal de Santa Maria - UFSM. \\ Santa Maria, Rio Grande do Sul - Brasil. \\ gabrielabruum96@gmail.com \\ Renato Xavier Coutinho \\ Doutor em Educação em Ciências \\ Instituto Federal de Educação, Ciência e Tecnologia Farroupilha - IFFar. \\ Santa Maria, Rio Grande do Sul - Brasil. \\ renato.coutinho@iffarroupilha.edu.br
}

\begin{abstract}
Resumo: A pesquisa trata-se de uma prática educativa realizada durante o ensino remoto, em virtude da expansão da Covid-19 e teve como objetivo analisar a contribuição do Cinema associada à metodologia de Experiência de Leitura por Andaimes no desenvolvimento dos conteúdos esporte e inclusão social; imigração, exclusão social e desemprego; e superação, perseverança e dedicação, referentes à disciplina de Educação Física. Utilizou-se o filme McFarland dos EUA. Participaram deste estudo de caso 27 estudantes do $1^{\circ}$ ano do Ensino Médio Integrado, de um Instituto Federal do Sul do Brasil. Ao analisar os dados, originaram-se duas categorias: pré-leitura: associação entre o esporte e a inclusão social na percepção dos estudantes e Situação social, realidade diversa e fatores primordiais para modificar a realidade e uma análise pós-leitura. Assim, conclui-se que a prática educativa possibilitou o desenvolvimento crítico, reflexivo e cultural dos estudantes, em relação ao conteúdo esporte.
\end{abstract}

Palavras-chave: cinema; educação física; ensino médio integrado.

\begin{abstract}
The research is an educational practice carried out during remote teaching, due to the expansion of Covid-19 and aimed to analyze the contribution of Cinema associated with the Scaffold Reading Experience methodology in the development of sport and social inclusion content; immigration, social exclusion and unemployment; and overcoming, perseverance and dedication, referring to the subject of Physical Education. The film McFarland from the USA was used. A case study was attended by 27 students from the 1st year of Integrated High School, from a Federal Institute in Southern Brazil. When analyzing the data, two categories were originated: pre-reading: association between sport and social inclusion in the students' perception and Social situation, diverse reality and primordial factors to modify reality and a post-reading analysis. Thus, it is concluded that the educational practice enabled the critical, reflective and cultural development of students, in relation to sport content.
\end{abstract}

Keywords: movie theater; physical education; integrated high school.

\section{Para citar - ABNT NBR 6023:2018}

ENCARNAÇÃO, Rosiele Oliveira; DEUS, Gabriela Brum; COUTINHO, Renato Xavier. Educação física e cinema: conteúdos didáticos e discussões sociais a partir da experiência de leitura por andaimes. Cadernos de Pós-graduação, São Paulo, v. 20, n. 2, p. 76-89, jul./dez. 2021. Disponível em: https://doi.org/10.5585/cpg.v20n2.19771. 
Introdução

O ano de 2020 tornou-se atípico, em consequência da pandemia da Covid-19, que expandiu e assolou o mundo, trazendo modificações em diversos setores da sociedade, inclusive, o contexto educacional, que precisou aderir, com urgência, o ensino remoto. $\mathrm{O}$ ambiente educacional teve que adaptar-se e estruturar seus currículos e práticas para aulas síncronas ou assíncronas, utilizando-se das Tecnologias Digitais da Informação e Comunicação (TDIC).

Entretanto, alguns componentes, que fazem parte do currículo do ensino médio, apresentam-se como um desafio maior, a exemplo da Educação Física (EF), que na maioria das vezes é bastante associada ao movimento e à prática dos esportes. Tal percepção pode estar vinculada ao que traz a Base Nacional Comum Curricular (BNCC) do Ensino Médio, quando destaca que a disciplina de EF:

[...] possibilita aos estudantes explorar o movimento e a gestualidade em práticas corporais de diferentes grupos culturais e analisar os discursos e os valores associados a elas, bem como os processos de negociação de sentidos que estão em jogo na sua apreciação e produção (BNCC, 2018, p. 483).

Em relação a isso, torna-se interessante a abordagem dos diversos conteúdos que fazem parte da sua estrutura curricular, utilizando-se de metodologias, recursos e práticas de ensino, visando romper alguns paradigmas, especialmente, de que a EF não se resume apenas à prática de esportes, mas também busca desenvolver os valores éticos e morais, além de discutir outras temáticas emergentes da sociedade. Por esse ângulo, Boscatto e Darido (2020) definem que a EF escolar vai além dos movimentos corporais, contribuindo com a formação para a vida. Como componente curricular da educação básica, a EF também está presente no Ensino Médio Integrado (EMI) aos cursos técnicos, que articula a educação profissional e técnica ao ensino médio, de forma omnilateral, no sentido de formar os sujeitos em sua integralidade mental, física, política, cultural e científico-tecnológica (FRIGOTTO; CIAVATTTA, 2011). Neste contexto, a EF necessita entrelaçar seus conhecimentos específicos aos conhecimentos de cada curso integrado, para formar técnicos capazes de exercer a cidadania (BOSCATTO, 2017).

Nesta perspectiva, o Cinema advém como uma alternativa para possibilitar a inserção de obras cinematográficas que permitam a reflexão e a discussão de problemáticas encontradas nos variados contextos sociais. Conforme Duarte (2009) salienta, com os objetivos e conteúdos adequados, o Cinema é um instrumento valioso, para trabalhar valores, crenças e visões de mundo dos diferentes grupos sociais.

Associado ao Cinema, a Experiência de leitura por Andaimes apresenta-se como uma metodologia de ensino capaz de estruturar as práticas que utilizam o Cinema, a fim de que os 
sujeitos consigam construir saberes ao longo de uma série de atividades. A Experiência de Leitura por Andaimes, no formato original, tem o objetivo de auxiliar no processo de leitura e compreensão de textos pelos alunos (GRAVES; GRAVES, 1995). Contudo, a partir do estudo de Encarnação (2020) identificou-se a potencialidade de articulação da metodologia com as obras cinematográficas nas práticas de sala de aula.

Diante do exposto, o presente estudo apresenta o desenvolvimento de uma prática educativa, realizada por meio do ensino remoto, tendo como objetivo analisar a contribuição do Cinema associada à metodologia da Experiência de Leitura por Andaimes para desenvolver os conteúdos esporte e inclusão social; imigração, exclusão social e desemprego; e superação, perseverança e dedicação, referentes à disciplina de Educação Física. A prática apoiou-se na atual BNCC, utilizando os conteúdos supracitados para possibilitar aos estudantes uma análise e uma compreensão das circunstâncias históricas, sociais e ideológicas de maneira reflexiva, crítica, dialógica e empática (BRASIL, 2018).

\section{Metodologia}

Trata-se de um estudo de caso, de abordagem qualitativa, com natureza prática e embasado na perspectiva explicativa (GIL, 2008). Segundo Yan (2015), o estudo de caso objetiva investigar um fenômeno atual, diante do seu contexto real. Tal investigação pode explorar as situações reais, descrever essas situações ou explicar as variáveis causais do fenômeno (GIL, 2008). Assim, referente à perspectiva explicativa destaca-se sua preocupação em "identificar os fatores que determinam ou que contribuem para a ocorrência dos fenômenos" (GIL, 2008, p. 28).

A intervenção pedagógica, envolvendo o cinema e a Experiência de Leitura por Andaimes foi desenvolvida nas aulas remotas da disciplina de EF, de um Instituto Federal do Sul do Brasil e teve como público-alvo 27 estudantes do $1^{\circ}$ ano do Curso Técnico em Agropecuária Integrado ao Ensino Médio. Para tanto, a metodologia de ensino utilizada foi a Experiência de Leitura por Andaimes, descrita por Graves e Graves (1995) e adaptada para a utilização com o Cinema conforme os estudos de Encarnação (2020), Encarnação e Coutinho (2018), e Encarnação, Paniz e Coutinho (2020). A metodologia é dividida em duas fases: planejamento e implementação.

No planejamento realizou-se o levantamento e a escolha do filme, bem como a elaboração das atividades. Assim, a obra cinematográfica selecionada foi o filme intitulado de: McFarland dos EUA. O filme foi lançado em 2015 e conta a história de um treinador que vai trabalhar em uma escola, localizada na cidade de McFarland, na Califórnia, tendo como tarefa trabalhar com um grupo de estudantes. A partir do enredo, o filme aborda aspectos econômicos, sociais e estruturais, além de aspectos que envolveram o esporte na formação pessoal e profissional dos estudantes. 
Nesse sentido, os conteúdos que envolveram a prática, foram: esporte e inclusão social; imigração, exclusão social e desemprego; e superação, perseverança e dedicação.

$\mathrm{Na}$ fase de implementação formaliza-se o desenvolvimento da prática e essa é dividida em três etapas de atividades: pré-leitura, leitura e pós-leitura. As atividades de pré-leitura apresentamse com o objetivo de motivar, bem como alicerçar o conhecimento prévio sobre determinado assunto, a fim de estimular no processo de construção de conhecimento (GRAVES; GRAVES, 1995). Na prática, a atividade consistiu em responder um questionário.

$\mathrm{Na}$ etapa de leitura, originalmente trabalha-se com textos, no entanto, na intervenção utilizou-se o filme selecionado na fase do planejamento, juntamente com um roteiro de acompanhamento, para que os estudantes identificassem os aspectos apresentados no roteiro ao assistir ao filme. Por fim, a etapa de pós-leitura é constituída por atividades com a finalidade de que os alunos sintetizem e organizem as informações do texto, e, nesse momento, o professor pode avaliar o entendimento dos alunos (GRAVES; GRAVES, 1995). Dessa forma, na prática, a pósleitura foi composta por um questionário, com o intuito de verificar as percepções dos estudantes sobre o filme em relação aos conteúdos abordados.

Para sistematizar a atividade utilizou-se de um plano de atividades, com direcionamento para questões a serem respondidas antes e depois de assistir ao filme. Destaca-se, que as questões antes do filme fizeram parte da etapa de pré-leitura; a leitura está representada pelo roteiro de acompanhamento, com conteúdos para observar durante a exibição do filme; e as questões após o filme constituíram a etapa de pós-leitura. A guia com as respectivas questões encontra-se descrita no Quadro 1.

Quadro 1 - Plano de atividades

\begin{tabular}{|c|c|c|}
\hline \multicolumn{3}{|r|}{ Plano de atividades } \\
\hline Pré-leitura & $\begin{array}{l}\text { Questão respondida } \\
\text { antes do filme }\end{array}$ & $\begin{array}{l}\text { 1) Quando se fala em inclusão social vem à mente de muita gente o esporte. A } \\
\text { prática esportiva é considerada como algo muito mais importante que apenas } \\
\text { uma atividade física ou fator de qualidade de vida. O esporte é capaz, de unir } \\
\text { diferenças entre povos e cooperar no processo de inclusão social. Assim sendo, } \\
\text { aponte dois argumentos que justifiquem a afirmação acima. }\end{array}$ \\
\hline Leitura & $\begin{array}{c}\text { Roteiro de } \\
\text { acompanhamento }\end{array}$ & $\begin{array}{l}\text { - Esporte e inclusão social; } \\
\text { - Imigração, exclusão social e desemprego; } \\
\text { - Superação, perseverança e dedicação. }\end{array}$ \\
\hline Pós-leitura & $\begin{array}{l}\text { Questões } \\
\text { respondidas depois } \\
\text { do filme }\end{array}$ & $\begin{array}{l}\text { 1) Qual a situação de vida dos estudantes da escola Mcfarland? } \\
\text { 2) A situação social deles está relacionada ao que? } \\
\text { 3) Como o professor se sentiu ao chegar na escola? } \\
\text { 4) Quais atitudes do professor e dos alunos foram necessárias para transformar } \\
\text { a realidade? }\end{array}$ \\
\hline
\end{tabular}

\footnotetext{
Fonte: Os autores.
} 
Além disso, foi solicitado para que os participantes construíssem uma síntese argumentativa após assistir ao filme. Tal síntese teve o seguinte enfoque: "O filme aborda temas como as dificuldades dos imigrantes nos EUA e como o esporte contribui no processo de inclusão social. A partir disso, qual a situação do filme que mais chamou sua atenção e por quê?”.

Os dados foram coletados via questionários e produção textual, sendo analisados pela análise de conteúdo (BARDIN, 2016), a fim de categorizar os elementos e possibilitar a visualização dos resultados da prática a partir da percepção dos estudantes. Para melhor elucidar, o fluxograma abaixo representa os procedimentos realizados neste estudo.

Figura 1 - Fluxograma do estudo e da prática

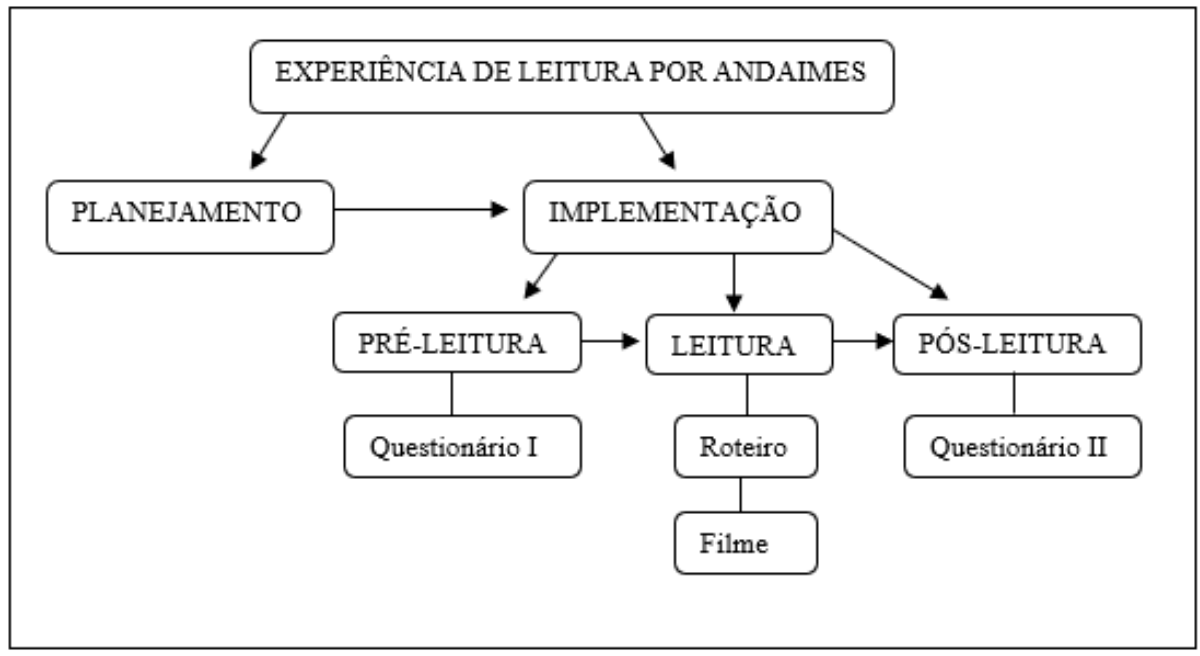

Fonte: Os autores.

\section{Resultados e discussões}

Os dados foram apresentados em duas seções, as quais emergiram durante a análise dos dados: 1) Pré-leitura: associação entre o esporte e a inclusão social na percepção dos estudantes; e, 2) Situação social, realidade diversa e fatores primordiais para modificar a realidade: uma análise pós-leitura. A referida organização torna possível a análise do processo de construção de conhecimentos dos estudantes, mediante às ações antes e depois da exibição do filme, destacandose o caminho percorrido na compreensão dos conteúdos trabalhados durante a prática educativa.

Pré-leitura: associação entre o esporte e a inclusão social na percepção dos estudantes

A etapa de pré-leitura equivale à primeira experiência de verificar alguns pontos em relação aos conhecimentos prévios dos estudantes. Assim, referente ao primeiro questionamento - relação entre inclusão social e esporte - emergiram quatro categorias, conforme a Tabela 1: 
Tabela 1 - Argumentos dos estudantes referente à inclusão social e o esporte, na etapa de préleitura

\begin{tabular}{c|l|c|c} 
Número & \multicolumn{1}{|c|}{ Categorias } & Frequência & Quantitativo \\
\hline 1 & Projetos de cunho social e de incentivo & $29,6 \%$ & 8 respostas \\
\hline 2 & União & $18,5 \%$ & 5 respostas \\
\hline 3 & Inclusão & $11,1 \%$ & 3 respostas \\
\hline 4 & Não responderam & $40,8 \%$ & 11 respostas
\end{tabular}

Fonte: Os autores.

Ao analisar a tabela é possível identificar que a categoria referente aos projetos de cunho social e de incentivo foi a mais destacada pelos estudantes $(29,6 \%)$, seguidos da união $(18,5 \%)$ e inclusão (11,1\%). Tais categorias trazem à tona alguns elementos a se discutir, principalmente sobre as relações da inclusão social e a prática esportiva, sendo visualizado como além de uma atividade física ou fator de qualidade de vida.

Quanto à categoria Projetos de cunho social e incentivo destaca-se o seguinte posicionamento:

Inúmeros projetos desenvolvidos no Brasil visam a inclusão, muitos têm décadas de história, e um grande histórico de "ajudas" (Aluno A).

Segundo Meireles et al. (2020) os projetos sociais apresentam-se como espaços de proteção social no sentido de democratizar a participação dos sujeitos, especialmente os jovens em situação de vulnerabilidade, sendo uma alternativa para diminuir a desigualdade, manter o bem-estar social, além de promover vivências diferentes e inclusivas. Nesse contexto, compreende-se que é importante discutir os valores sociais do esporte com os estudantes, no intuito de que eles consigam relacionar o contexto social, além da capacidade de desenvolverem-se como sujeitos críticos, compreendendo o esporte como um fenômeno sociocultural.

Em relação à categoria União, ressalta-se o desenvolvimento dos valores pedagógicos do esporte, demonstrando que a partir do esporte é possível problematizar valores, atitudes e competências essenciais da vida em sociedade (BOSCATTO, 2017). Assim, o apontamento abaixo corrobora com tal pensamento:

Através do esporte, indivíduos de diferentes classes sociais e raciais, se dedicam de forma a fazê-los capazes de interagir entre si. Também, pode ajudar pessoas a criar sonhos e objetivos para uma qualidade de vida muito melhor (Aluno B). 
Diante do exposto, identifica-se que a prática educativa permitiu trabalhar o esporte como um meio para discutir com os estudantes elementos essenciais para atuar de forma responsável em comunidade. Ademais, quando trabalha-se com planejamento e intencionalidade o esporte possibilita uma aprendizagem mais significativa, se distanciando dos conteúdos tradicionais.

Em relação à categoria Inclusão, tem-se o esporte como um dispositivo para possibilitar as interações entre as diferentes classes sociais e raciais, com viés de auxiliar a inclusão desses sujeitos, bem como alicerçar aspectos referentes à união desses grupos, em busca de um objetivo em comum. Assim, o esporte vai além de apenas uma prática no componente curricular EF, mas passa a ser visto como uma alternativa de emancipação de sujeitos. Sendo a inclusão diretamente relacionada ao processo de emancipação. Nesse sentido, Santos e Nista-Picollo (2011) destacam o compromisso dos professores de EF em viabilizar práticas mais significativas ao abordar o ensino dos esportes, de modo que a prática esportiva do ensino médio retrate seus aspectos culturais e sociais, contribuindo com a formação dos estudantes.

Ao observar a tabela, também foi possível identificar que o quantitativo de estudantes que não responderam o questionamento foi expressivo. Esse fator pode ser reflexo das dificuldades do ensino remoto, dado que a $\mathrm{EF}$ no ensino médio de forma remota foi uma realidade imposta para amenizar os efeitos da pandemia da Covid-19. Assim, pontua-se a utilização de diversas metodologias para possibilitar uma interação entre os estudantes e dos estudantes com o professor durante este período de distanciamento, além de oportunizar a discussão de problemáticas que envolvam a realidade dos jovens.

\section{Situação social e fatores para transformar a realidade: uma análise pós-leitura}

$\mathrm{Na}$ etapa de pós-leitura ocorreu a sistematização das problemáticas abordadas no filme e ressaltadas pelos estudantes no roteiro de acompanhamento. Desta forma, o roteiro se caracterizou como um guia para direcionar os aspectos da EF, expostos na obra cinematográfica. Assim, ao longo desta seção foram discutidas as respostas dos estudantes, as quais foram agrupadas e categorizadas.

Ao questionar os participantes sobre a situação de vida dos estudantes retratada no filme, foi possível organizar as respostas em duas categorias, conforme elencado na Tabela 2.

Tabela 2 - Argumentos dos estudantes referente à inclusão social e o esporte

\begin{tabular}{c|l|c|c} 
Número & \multicolumn{2}{|c|}{ Categorias } & Frequência \\
\hline 1 & Condições sociais e condições de trabalho & $88,9 \%$ & 24 respostas \\
\hline 2 & Preparo físico & $11,1 \%$ & 3 respostas
\end{tabular}

Fonte: Os autores. 
Identifica-se que todos os estudantes responderam a esse questionamento e que $88,9 \%$ referem-se às questões que envolvem as condicões sociais e condições de trabalho, conforme evidencia o seguinte relato:

Eles precisam trabalhar todos os dias no campo colhendo para ajudar seus pais, nas despesas em casa (Aluno C).

Estudantes pobres do campo com pouco tempo para estudar, pois tinham que trabalhar para ajudar em casa sem perspectiva de vida melhor, sem perspectiva de fazer uma faculdade, apenas estudar o tempo necessário e depois só trabalhar (Aluno D).

Percebe-se, que o filme, ao trazer questões referente ao trabalho e às condições sociais dos personagens, provoca reflexões sobre o contexto social, especialmente, na interferência que a realidade provoca nas práticas e nas relações, no sentido de o trabalho ser considerado apenas uma prática de sobrevivência. Além da carência de perspectiva de emancipação, possibilitando a percepção de nuances da sociedade, referentes às questões econômicas, estruturais e sociais.

Além disso, a prática educativa também possibilitou desenvolver o esporte como um conteúdo pedagógico, ultrapassando a dimensão prática. Ao retratar de maneira reflexiva a realidade vivenciada por muitos estudantes.

Nesse sentido, Darido e Souza Júnior (2015) apresentam que a EF no currículo escolar deve levar em conta conteúdos numa dimensão mais biológica - como as relações entre nutrição e o esporte - seguido de uma dimensão mais sociocultural - como as relações entre esporte, sociedade e interesses econômicos, a organização social. Referente à situação social dos estudantes do filme e a que ela está relacionada, foi possível identificar quatro categorias (Tabela 3), sendo que 77,8\% das respostas destacaram que a situação social está diretamente relacionada às condições vinculadas ao trabalho.

Tabela 3 - Argumentos dos estudantes referentes à situação social retratada no filme

\begin{tabular}{c|l|c|c} 
Número & \multicolumn{1}{|c|}{ Categorias } & Frequência & Quantitativo \\
\hline 1 & Condições vinculadas ao trabalho & $77,8 \%$ & 21 respostas \\
\hline 2 & Condições vinculadas ao preparo físico & $14,8 \%$ & 4 respostas \\
\hline 3 & Condições relacionadas às atitudes & $3,7 \%$ & 1 resposta \\
\hline 4 & Não responderam & $3,7 \%$ & 1 resposta
\end{tabular}

Fonte: Os autores. 
Em relação às condições vinculadas ao trabalho, destaca-se o seguinte argumento:

[...] cidade pequena de interior baseada na agricultura, onde apenas os "senhores" de melhores condições comandam nos campos. As pessoas ganham baixos salários colaborando para mais pobreza (Aluno F).

Em relação à terceira pergunta, referindo-se ao sentimento do professor ao chegar na escola, foram identificadas quatro categorias, transcritas na Tabela 4.

Tabela 4 - Argumentos dos estudantes referente ao sentimento do professor ao chegar na escola

\begin{tabular}{c|l|c|c} 
Número & \multicolumn{1}{|c|}{ Categorias } & Frequência & Quantitativo \\
\hline 1 & Realidade social diferente & $51,9 \%$ & 14 respostas \\
\hline 2 & Adaptou-se para a realidade dos alunos & $25,9 \%$ & 7 respostas \\
\hline 3 & Percebeu talento nos alunos & $18,5 \%$ & 5 respostas \\
\hline 4 & Não responderam & $3,7 \%$ & 1 resposta
\end{tabular}

Fonte: Os autores.

O principal apontamento foi caracterizado como um sentimento de surpresa, especialmente por tratar-se de uma realidade social diferente $(51,9 \%)$, conforme o relato abaixo:

O professor estranhou o lugar pois não estava acostumado com aquele tipo de realidade (Aluno G).

Nessa perspectiva, pontua-se que o contraste de realidades trouxe conflitos e algumas dificuldades de imersão do professor no contexto. Porém, ao longo do processo, a postura e o posicionamento foram mudando, por conta da percepção do mesmo frente à possibilidade de emancipação dos alunos pelo esporte.

Quanto à segunda categoria mais evidenciada pelos estudantes $(25,9 \%)$, identifica-se a adaptação do professor para a realidade dos alunos, como destacado pelo Aluno D:

No início teve dúvidas se era o lugar certo para ele e a família, pois, o lugar e as pessoas eram diferentes do que ele estava acostumado, mas com o andar dos dias, ele começou a se adaptar e então ajudar os alunos a melhorar suas vidas através do esporte (Aluno D).

Desta forma, apresenta-se a adaptação como um fator norteador para possibilitar conhecer o contexto de vida, para, assim, intervir naquela realidade, e, então, para provocar nos sujeitos a transformação da sua realidade, a emancipação social e a quebra de paradigmas referentes aos aspectos sociais e econômicos. "Ou seja, o que deve ser trabalhado não é apenas a modalidade esportiva, mas o ser social, o intelecto e os valores" (GONZALEZ; PEDROSO, 2012, p. 1). 
O penúltimo questionamento buscou identificar as atitudes necessárias, tanto do professor quanto dos estudantes, para modificar a realidade (Tabela 5).

Tabela 5 - Atitudes necessárias para transformar a realidade

\begin{tabular}{c|l|c|c} 
Número & \multicolumn{1}{|c|}{ Categorias } & Frequência & Quantitativo \\
\hline 1 & Atitudinal/Comportamental & $59,3 \%$ & 16 respostas \\
\hline 2 & Procedimentos com viés lucrativo & $37 \%$ & 10 respostas \\
\hline 3 & Não responderam & $3,7 \%$ & 1 resposta
\end{tabular}

Fonte: Os autores.

Após verificar as respostas, identificou-se três categorias, com destaque para a categoria Atitudinal/Comportamental (59,3\%), conforme os seguintes relatos:

As atitudes necessárias foram muito treino, união e solidariedade (Aluno I).

Dedicação, esperança de que aqueles alunos eram melhores do que pensavam, e a união entre eles e o apoio que tiveram, foi o que lhes deu coragem para continuar seus treinos e buscar a vitória (Aluno J).

Nesse contexto, destaca-se a compreensão da EF na escola como um componente curricular que alicerça o desenvolvimento das competências socioemocionais juntamente das competências físicas e cognitivas. No entanto, para isso, as práticas devem ser orientadas por docentes cientes do seu papel formador e do ato pedagógico, levando ao protagonismo e à açãoreflexão dos/entre os estudantes (MEIRELES et al., 2020).

Diante dos relatos, também ficou evidente que, por meio do filme, foi possível desenvolver o esporte no seu sentido motivacional, indo além daquela concepção de que o esporte escolar é mera recreação ou voltado ao rendimento. Demonstrando o importante papel do esporte no desenvolvimento do companheirismo, da cooperação e da superação de suas próprias dificuldades e da equipe.

Em relação a categoria Procedimentos com viés lucrativo, nota-se que para alcançar o objetivo os estudantes tiveram que trabalhar em equipe, vendendo comida e lavando carros, conforme o relato abaixo:

Eles começaram a fazer comidas e montaram um estilo de lava-jato, para quem quisesse levar os carros para eles conseguirem dinheiro (Aluno L).

Diante do exposto, é possível discutir aspectos comuns entre o esporte e a vida cotidiana (atual e futura) dos estudantes, demonstrando que a partir dos conteúdos e das práticas corporais 
da disciplina de EF, ela pode contribuir com o desenvolvimento de habilidades e valores fundamentais para sua formação. Nesse contexto, Marques e Gawryszewski (2018) ressaltam, especialmente aos estudantes do EMI, a necessidade de relacionar os aspectos comuns do mundo do trabalho, da disciplina de EF e da formação integral, tais como competitividade, liderança, cooperação, trabalho em equipe e tomada de decisões. Em relação à formação integral, Ramos (2014) aprofunda que o viés visa superar a concepção do ser humano, reduzido apenas a divisão social do trabalho no seu sentido operacional, dedicado sumariamente a execução, rompendo tal propósito para uma concepção de formação humana, no sentido de integração de todas as dimensões da vida no processo educativo, visando à formação omnilateral dos sujeitos.

Assim, destaca-se a importância da compreensão crítica sobre os conteúdos da EF, no sentido de o estudante compreender, praticar, vivenciar e discutir os aspectos socioculturais inerentes às práticas corporais (BOSCATTO; DARIDO, 2017). Para finalizar, a síntese argumentativa proporcionou um espaço para os estudantes se posicionarem frente às questões apresentadas no filme (Tabela 6).

Tabela 6 - Posicionamento dos estudantes em relação às questões abordadas no filme

\begin{tabular}{c|l|c|c} 
Número & \multicolumn{1}{|c|}{ Categorias } & Frequência & Quantitativo \\
\hline 1 & Atitudes do professor e dos alunos & $33,4 \%$ & 9 respostas \\
\hline 2 & Atitudes do professor & $22,2 \%$ & 6 respostas \\
\hline 3 & Atitudes dos alunos & $22,2 \%$ & 6 respostas \\
\hline 4 & Não responderam & $22,2 \%$ & 6 respostas
\end{tabular}

Fonte: Os autores.

Observa-se, que as respostas apontaram categorias referentes às atitudes do professor e dos alunos. Segundo os relatos, ambos foram persistentes, o professor foi dedicado e os estudantes conseguiram superar suas limitações:

A persistência dos alunos e do professor, pois eles não desistiram dos sonhos deles (Aluno M).

[...] o que mais me chamou atenção no filme foi a forma com que ele se dedicou em ajudar os garotos, mesmo com as dificuldades (Aluno $\mathrm{H}$ ).

$\mathrm{Na}$ parte que os sete concorreram no estado, porque eles não desistiram, foram até o fim com garra e superação (Aluno L). 
Deste modo, identifica-se na categoria atitudes referentes aos valores externalizados e percebidos pelos sujeitos participantes da presente ação, nas práticas esportivas da EF representadas no filme, dentre as atitudes destaca-se a persistência, a dedicação e a superação. Segundo, Meireles et al. (2020, p. 79) o esporte:

[...] pode contribuir para níveis mais altos de saúde mental, quando proporciona momento de encontros que pode auxiliar no desenvolvimento de habilidades sociais (lidar com críticas, melhorar a comunicação entre as pessoas, dar e receber feedback), criar vínculos de amizade, contato com pessoas que incentivam, motivam, inspiram. Além de contribuir para o incremento de habilidades como concentração, resolução de problemas e administração das emoções.

Diante do exposto, Barros e Darido (2009) consideram conteúdos de aprendizagem aqueles que permitem o desenvolvimento das capacidades motoras, afetivas, bem como as relações interpessoais e a perspectiva de inserção social. Por fim, a partir dos dados apresentados evidenciase a potencialidade do Cinema para trabalhar com temáticas relacionadas à disciplina de Educação Física.

Tinôco (2017) corrobora que no ensino dos esportes, o Cinema se caracteriza como uma estratégia pertinente, por possibilitar o desenvolvimento crítico, reflexivo e cultural dos estudantes. Infelizmente, essa união - cinema, esporte e EF - não é tão recorrente dentro do contexto escolar, em virtude da falta de formação adequada aos docentes, questões estruturais, históricas e culturais, entre outros (TINÔCO, 2017).

Nesse sentido, é importante desenvolver maiores discussões sobre essa relação, pois como apresentado anteriormente, os estudantes conseguiram relacionar os conteúdos da EF com os aspectos da vida cotidiana. Assim, destaca-se a necessidade de se refletir sobre a importância da EF no contexto escolar e na formação do indivíduo, enfatizando que a EF contribui de forma ativa na formação de cidadãos mais humanos, éticos, responsáveis, justos e saudáveis (BEGO; ANJOS, 2020).

\section{Conclusão}

A partir dos resultados da prática relatada, pontua-se que a Experiência de Leitura por Andaimes associada ao filme possibilitou uma discussão sobre as temáticas do componente curricular de Educação Física do EMI, durante o período remoto. Ademais, foi possível relacionar os conteúdos com as temáticas sociais - inclusão social, vulnerabilidade social, exclusão social e desemprego, imigração - além de aspectos de origem atitudinal - superação, perseverança e dedicação. Desta forma, o filme apresentou temáticas vivenciadas pelos alunos no seu cotidiano e 
tal exercício possibilitou a reflexão do papel e das ações desses sujeitos frente à resolução de dificuldades.

Por fim, quanto à utilização da Experiência de Leitura por Andaimes associada ao Cinema, nas aulas de EF do EMI, ressalta-se o potencial dessa metodologia não exclusivamente no ensino remoto, mas também no pós-pandemia do Covid-19, em virtude de viabilizar aos conteúdos da EF, como, por exemplo, o esporte que é normalmente limitado a execução da prática motora e as discussões relacionando o esporte às lacunas sociais. Deste modo, é possível ir além dos aspectos básicos do currículo e contribuir com a formação integral dos sujeitos.

\section{Referências}

BARDIN, L. Análise de conteúdo. $3^{\mathrm{a}}$ reimp. 1ª ed. São Paulo: Edições 70, 2016.

BARROS, A. M; DARIDO, S. C. Práticas pedagógicas de dois professores mestres em educação física escolar e o tratamento da dimensão conceitual dos conteúdos. Rev. bras. Educ. Fís. Esporte, São Paulo, v. 23, n. 1, p. 61-75, jan./mar., 2009. Disponível em: https://www.revistas.usp.br/rbefe/article/view/16711/18424. Acesso em: 26 de fev. 2021.

BEGO, G. A.; ANJOS, J. R. C. A importância da educação física escolar para a formação do indivíduo na sociedade. Revista Saúde UniToledo - Araçatuba - SP, v. 4, n. 1, p. 13-26, jul. 2020. Disponível em: http://www.ojs.toledo.br/index.php/saude/article/view/3557. Acesso em: 8 de mar. 2021.

BOSCATTO, J. D. Proposta curricular para a educação física no Instituto Federal de Santa Catarina: uma construção colaborativa virtual. Tese. $164 \mathrm{f}$. (Doutorado em Desenvolvimento Humano e Tecnologias) - Universidade Estadual Paulista (UNESP), Rio Claro, SP, 2017. Disponível em: https://repositorio.unesp.br/handle/11449/151896. Acesso em: 4 de mar. 2021.

BOSCATTO, J. D.; DARIDO, S. C. A Educação Física nos institutos federais: "o quê" e o "para quê" ensinar? Motrivivência, Florianópolis, v. 32, n. 63, p. 01-17, jul. 2020. Disponível em: https://periodicos.ufsc.br/index.php/motrivivencia/article/view/2175-8042.2020e72210. Acesso em: 5 de mar. 2021.

BRASIL. Ministério da Educação. Base Nacional Comum Curricular - Versão final. Brasília, Distrito Federal, 2018.

DARIDO, S. C.; SOUZA JÚNIOR, O. M. Para ensinar educação física: Possibilidades de intervenção na escola, Campinas, SP: Papirus, 2015.

DUARTE, R. Cinema \& educação. $3^{a}$ Ed. Belo Horizonte: Autêntica Editora, 2009. p.104.

ENCARNAÇÃO, R. O. Utilizando o cinema como ferramenta didática no ensino de Ciências Naturais. Dissertação. 99 p. (Mestrado em Educação em Ciências: Química da Vida e Saúde) Universidade Federal de Santa Maria (UFSM), Santa Maria, RS, 2020. 
ENCARNAÇÃO, R. O; COUTINHO, R. X. O Ensino de mecânica através do cinema. Experiências em Ensino de Ciências, v.13, n..5, p. 59 -72, dez, 2018. Disponível em: https://if.ufmt.br/eenci/artigos/Artigo_ID527/v13_n5_a2018.pdf. Acesso: 8 mar. 2021.

ENCARNAÇÃO, R. O.; COUTINHO, R. X. PANIZ, C.M. Uma experiência com Cinema na formação Inicial de professores de Ciências Biológicas. In: MACHADO, G.E.; OLIVEIRA, V.M.F. (Organizadoras). Cinema e educação: experiências estéticas de ensino e aprendizagens com a sétima arte. $1^{a}$ edição. Rio de Janeiro: Eulim, v.1, n. 1, p. 50-79, 2020. Disponível em:

https://drive.google.com/file/d/1EPVHHjLC7LIsmTWN-S7Qg-Iw_IPm19F1/view. Acesso: 8 mar. 2021.

FRIGOTTO, G.; CIAVATTA, M. Perspectivas sociais e políticas da formação de nível Médio: avanços e entraves nas suas modalidades. Educ. Soc., Campinas, v. 32, n. 116, p. 619-638, set., 2011. Disponível em: https://www.scielo.br/pdf/es/v32n116/a02v32n116.pdf. Acesso em: 29 mar. 2021.

GIL, A. C. Métodos e técnicas de pesquisa social. 6ª ed. - São Paulo: Atlas, 2008.

GONZALEZ, N. M.; PEDROSO, C. A. M. Q. Esporte como conteúdo da Educação Física: a ação pedagógica do professor. EFDeportes.com, Revista Digital. Buenos Aires, v. 15, n. 166, p.1p.16, mar. 2012. Disponível em: https://www.efdeportes.com/efd166/esporte-como-conteudoda-educacao-fisica.htm. Acesso em: 30 mar. 2021.

GRAVES, M. F.; GRAVES, B. B. The scaffolded reading experience: a flexible framework for helping students get the most out of text. Reading, v.29, n. 1, p. 29-34, abril, 1995.

MARQUES, G. S.; GAWRYSZEWSKI, B. A Educação Física e suas possibilidades no Ensino Médio Integrado. Germinal: Marxismo e Educação em Debate, Salvador, v. 10, n. 2, p. $166-$ 174, 2018.

MCFARLAND DOS EUA. Direção: Niki Caro. Produção: Mark Ciardi e Walt Disney Pictures. Estados Unidos. 2015. 129 minutos.

MEIRELES, et al. Projetos esportivos sociais para adolescentes no Brasil: impactos, implicações e barreiras. Caderno de Educação Física e Esporte, Marechal Cândido Rondon, v. 18, n. 1, p. 77-82, jan./abr. 2020. Disponível em: http://e-

revista.unioeste.br/index.php/cadernoedfisica/article/view/24020/pdf. Acesso: 8 mar. 2021.

RAMOS, M. N. História e política da educaşão profissional. [Recurso eletrônico]. Curitiba: Instituto Federal do Paraná (Coleção formação pedagógica; v. 5, n.1), 121 p., 2014. Disponível em: https:// curitiba.ifpr.edu.br/wp-content/uploads/2016/05/Hist\%oc3\%b3ria-e-pol\%oc3\%adticada-educa \%c3\%a7\%c3\%a3o-profissional.pdf. Acesso em: 30 de mar. 2021.

SANTOS, M. A. G. N.; NISTA-PICOLLO, V. L. O esporte e o ensino médio: a visão dos professores de educação física da rede pública. Rev. bras. Educ. Fís. Esporte, São Paulo, v. 25, n. 1, p. 65-78, jan./mar. 2011. Disponível em: https://www.scielo.br/pdf/rbefe/v25n1/08.pdf. Acesso em: 29 de mar. 2021.

TINÔCO, R. G. Educação Física escolas \& Cinema: experimentando novas formas de ensinar esporte no ensino médio. Dissertação. 190 f. (Mestrado em Educação Física) - Universidade Federal do Rio Grande do Norte (UFRN), Natal, RN, 2017. Disponível em: https://repositorio.ufrn.br/handle/123456789/23469. Acesso em: 8 de mar. 2021.

YAN, R. K. Estudo de caso: planejamento e métodos. 5a ed. - Porto Alegre: Bookman, 2015. 